\title{
Five Minutes After Death: A Study of Beliefs and Expectations
}

\author{
Allan Kellehear, Ph.D. \\ La Trobe University \\ Harvey Irwin, Ph.D. \\ University of New England
}

ABSTRACT: This paper examines the beliefs and expectations that a sample of 508 people hold about the first five minutes after death. A substantial minority believed that they will experience the main elements of the neardeath experience (NDE). In general these elements were cited more frequently than were Biblical images. Six percent of the sample said that postmortem survival for them will be a negative and disturbing experience. We discuss these results in terms of their methodological implications for other survey work and their theoretical contribution toward our understanding of negative NDEs.

What, if anything, do people believe about experiences associated with the first five minutes after their own death? This paper examines the nature of popular beliefs and expectations about the initial moments of postmortem existence. Studying beliefs about personal survival of death is relevant to near-death research for two reasons.

First, these beliefs may reflect aspects of socialization and social conditioning, which in turn may influence to some extent the content and nature of the near-death experience (NDE). For example, Calvin Schorer (1985-86) noted of native American NDE accounts that the panoramic life review is absent but traditional images such as the

Dr. Kellehear is Lecturer in Sociology at La Trobe University, and Dr. Irwin is Associate Professor of Psychology at the University of New England. Reprint requests should be addressed to Dr. Kellehear at the Department of Sociology, La Trobe University, Bundoora, 3083, Australia. 
flathead snake, the "war eagle," deer, moose, and bows and arrows are encountered. Dorothy Counts (1983) described an event within a Melanesian NDE in which a deceased acquaintance cut the leg of the $\mathrm{NDEr}$ and spat ginger on it. Counts noted that "spitting ginger on a wound is a traditional healing practice ... thought to have great healing power" (1983, p. 119). Satwant Pasricha and Ian Stevenson (1986) noted several culture-specific features of their Indian accounts, including being "sent back" because of mistaken identity and the reading of the record of a person's life. However, they cautioned against the reductionist implication that these variations are purely a function of prior beliefs and socialization.

We should remember, however, that if we survive death and live in an afterlife realm, we should expect to find variations in that world, just as we find them in the different parts of the familiar world of the living. A traveller to Delhi encounters dark skinned immigration officials, who in many respects behave differently from the lighter skinned immigration officials another traveller may meet when arriving in London or New York. Yet we do not say that the descriptions of the first traveller are "real" and those of the second "unreal." (Pasricha \& Stevenson, 1986, p. 169)

This caution notwithstanding, the observed cross-cultural variations in NDE content do prompt further empirical scrutiny of the possibility that the phenomenology of the experience is inspired to some degree by processes of social conditioning.

Another reason for exploring beliefs with respect to the NDE is that even if the relationship between social beliefs and the content of an NDE is causally ambiguous, social beliefs will nonetheless be important to the interpretation of the NDE by NDErs and their social network. For example, NDErs frequently depict elements of their NDE in terms of some aspect of their religious belief. Kenneth Ring (1980) reported cases where "the light" was described as a "vision of Jesus." Of course, it is not necessarily the characteristics of the phenomenon that are important for this identification but rather the NDErs' interpretation of what they believe they experience. Furthermore, not all NDErs will necessarily interpret their experience as a brief glimpse of the afterlife. The English philosopher Sir A.J. Ayers, in his much publicized account (1988) of his own NDE was happy to view that experience as a side effect of brain activity secondary to his cardiac arrest. Although in his view survival is a philosophic question worth entertaining, Ayers wrote that persistence of brain activity is by far the "most probable explanation." This is a similar interpretation to that 
taken by some respondents in a Chinese survey (Kellehear, Heaven \& Gao 1990). Of the 26 respondents who claimed to have had an experience similar to the NDE described in that survey, only 6 chose to construe it as evidence of life after death. It is within the context of these issues and possibilities that the present study is set.

\section{Background to the Study}

In 1987 Harvey Irwin examined stereotypical images of heaven and compared these with the common images and experiences reported in NDEs. Past surveys had given little attention to beliefs about the appearance of the afterlife environment and that confined the area to speculation. In the Irwin survey questionnaires were distributed to 96 university students. They were asked to take an imaginary tour through heaven and check off any statements on the survey form that fairly represented their impressions. The survey covered four areas: the physical appearance of heaven, beings that might be encountered, the major mode of travel, and the sounds one might hear in that environment.

There were several features in that survey that limit any subsequent comparison with its findings and the NDE. First, a study of the beliefs of the afterlife might not necessarily indicate beliefs about the first five minutes of after-death experience. Indeed, theologian John Hick (1976) rightly identified eschatology as the doctrine of last things or of the ultimate state to which we are destined. He used the term pareschatology to designate the doctrine of next-to-last things or the "human future between the present life and Man's ultimate state" (Hick 1976, p. 22). It is pareschatological beliefs about the very next stage of existence beyond the present that we sought to examine here. This is important because people who believe in heaven may have a poorly developed idea of the experiential steps between this life and paradise. Conversely, people with beliefs about the experience of death itself may have poorly developed ideas about their ultimate destination and resting place in the "next world."

Second, Irwin's study employed a checklist of items developed from a pilot of 16 people. Checklists have the advantage of prompting poorly motivated respondents but they also restrict the potential diversity of images and experiences people may draw upon. In addition checklists, including those with token provision for answers not covered by the list, direct and channel respondents' thinking along set lines.

Finally, Irwin's study did not survey the emotional dimension. 
Sights, sounds, encounters, and travel were explored in the imaginary trip through heaven, but feelings about being in heaven were not addressed. This is an important omission since the NDE is typically characterized by powerful positive or negative emotion.

The aims of this study, therefore, were to solicit beliefs and expectations about the first five minutes after death; to conduct this study by using a semistructured instrument; and to document and examine people's beliefs and expectations about their own emotional reactions to this time.

The research was divided into two parts, which, for reasons of clarity and organization, are called Study 1 and Study 2 . Study 1 documents beliefs about postmortem existence insofar as respondents in this study held them. Study 2 explores expectations about personal survival regardless of the beliefs held by those in this sample. The rationale behind Study 2 is the recognition that experiences might be shaped not only by beliefs but also knowledge. In this respect, NDEs also occur among those who do not believe in postmortem survival of any kind. Directing respondents to construct images of the afterlife, despite their personal beliefs, should tap this source of expectations.

\section{Study 1}

\section{Sample}

Two groups were surveyed for their beliefs about the first five minutes after their own deaths. The first group comprised 262 first year undergraduate students at an Australian university. There were 41 males, 219 females and two whose gender was not specified. The mean age was 21 and the majority of these students were studying social science (101) or nursing (137).

After the student survey, volunteers were requested to distribute questionnaires among the general population. This was the second group for the study $(N=72)$. Student volunteer survey assistants were asked to sample adults from the local community and to select from as broad a range as possible in terms of age and socioeconomic status. The sample was evenly divided between males (35) and females (35), with two whose gender was not specified. The mean age for this sample was 38. One respondent had achieved primary education level, 30 had achieved secondary level, 19 obtained secondary and further technical training, 17 had some level of university or college education, and 5 did 
not specify educational level. The people in this sample came from a wide variety of occupations, ranging in occupational prestige scores from 2.4 to 6.6 with a possible range between 1.2 to 6.9 using Ann Daniel's (1983) occupational prestige scale.

\section{Questionnaire}

Respondents were asked three questions. The first question was fixed choice and the others were open ended. Question 1 enquired about the respondent's belief in survival in the first five minutes after biological death. Response options were "yes," "no," or "unsure." If respondents answered "yes" to this question they were directed to answer question 2.

Question 2 was set in the context of their belief in surviving the first five minutes after death. Respondents were asked to complete four sentences. These were: "Within these very first moments, I believe I will see. ..."; "I believe I will meet. . . ."; "I believe I will hear. ..."; "Emotionally, I will feel...."

Regardless of their answer to question 1, all respondents were asked to answer question 3 , which asked them to identify the social influences they believed were important to the kind of answer they gave in question 1 . Students were also asked their sex, age, and field of study. The community group were asked their sex, age, education, and occupation.

\section{Results}

The distribution of responses to question 1 , on the belief of postmortem existence, is presented in Table 1. The two samples differ in their distribution here $\left(\mathrm{X}^{2}=13.96, \mathrm{df}=2 ; \mathrm{p}<.001\right)$. There is a trend

Table 1

Belief about surviving the first five minutes after death-Study 1

\begin{tabular}{lrc}
\hline & $\begin{array}{c}\text { Students } \\
(N=262)\end{array}$ & $\begin{array}{c}\text { Community } \\
(N=72)\end{array}$ \\
\hline will survive & $104(40 \%)$ & $33(46 \%)$ \\
will not survive & $34(13 \%)$ & $20(28 \%)$ \\
unsure & $124(47 \%)$ & $19(26 \%)$ \\
\hline
\end{tabular}


for a substantial proportion of the student group, who are younger than the community group, to say they were "unsure" about postmortem experience. Perhaps as people grow older they take a more definite stance on this issue.

The believers, who responded "yes" to question 1 in the two samples (104 students and 33 members of the community sample), were asked what they believed they would see, meet, hear, and feel in the first five minutes of their postmortem existence. "Don't know, no answer" responses for the student sample ranged from $12 \%$ for one category to $31 \%$ for two others. The response of "don't know" was somewhat lower in the general sample, ranging from $3 \%$ for one category to $27 \%$ for another. The full range of generic responses is summarized in Table 2. The similarity between these responses and the usual elements of the NDE is notable. What believers declare they will see, meet, hear, and feel in the first five minutes after death tends to correspond closely to the typical NDE.

Believers (137) and nonbelievers (54) were asked to identify the likely sources of their beliefs. Their answers are summarized in Table 3 . Although relatively few believers gave Biblical or heavenly depictions of the postmortem experience, a substantial proportion of believers cited the Bible and various forms of religious instruction as the alleged source of their beliefs. The sources of belief in the existence of an afterlife evidently are in some degree distinct from the sources of belief in the nature of the afterlife. Accounts of NDEs nevertheless represent another significant declared source of believers' understanding of postmortem experience. This is not surprising given that an estimated $72-79 \%$ of Australians are familiar with the NDE (Kellehear \& Heaven 1989).

In both samples there is some tendency for nonbelievers to portray themselves as independent thinkers, claiming to form their attitude to an afterlife in terms of their own observations and logic rather than on the basis of other people's suggestions and influence.

\section{Study 2}

\section{Sample}

A second group of first-year undergraduate Australian university students was asked to complete a questionnaire concerning their expectations about postmortem existence, irrespective of their beliefs in 


\section{Table 2}

Incidence of reported beliefs about

postmortem experience-Studies 1 and 2

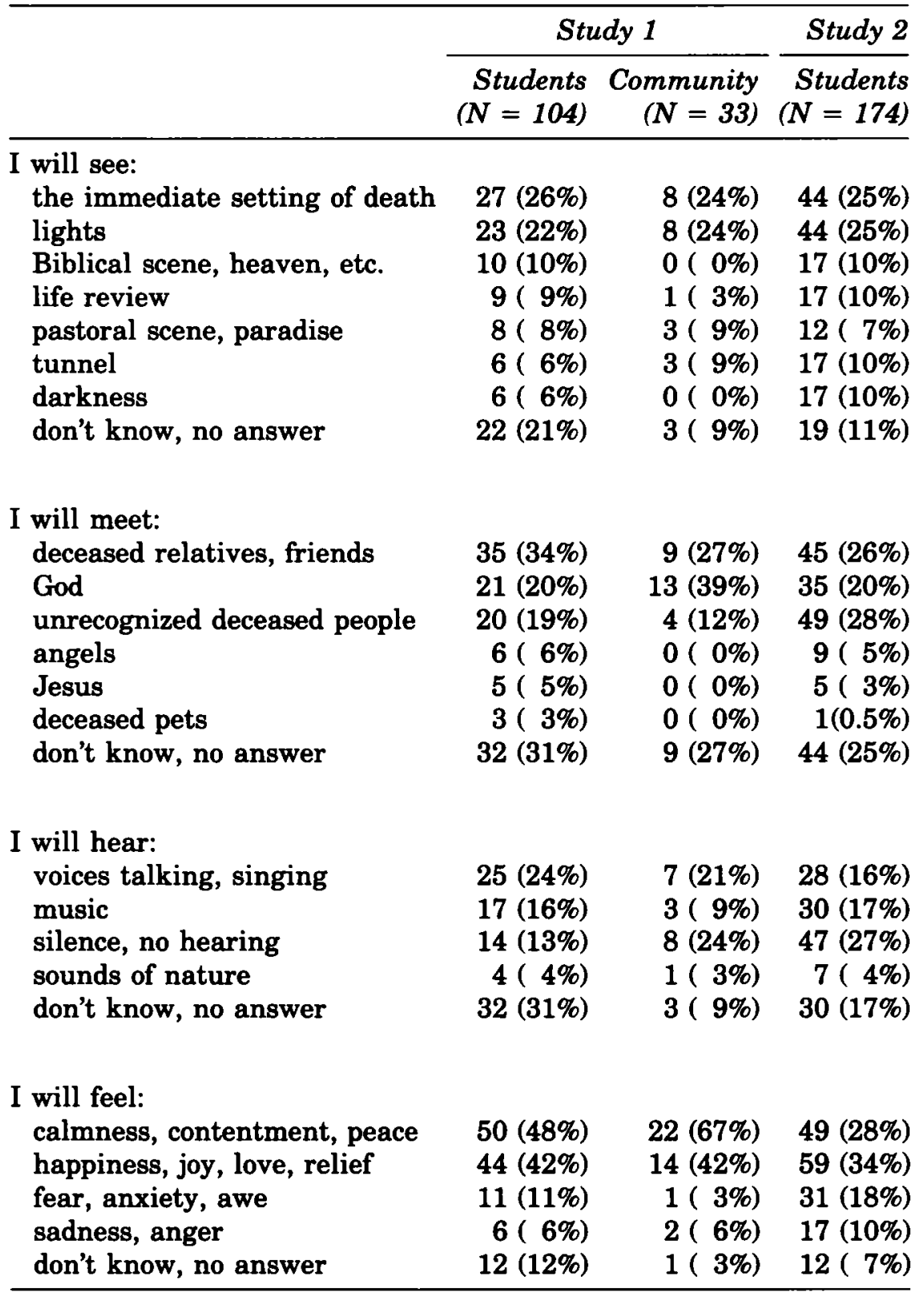




\section{Table 3}

Incidence of declared sources of belief-Study 1

\begin{tabular}{|c|c|c|c|c|}
\hline & \multicolumn{2}{|c|}{ Students } & \multicolumn{2}{|c|}{ Community } \\
\hline & $\begin{array}{l}\text { Believers } \\
(N=104)\end{array}$ & $\begin{array}{c}\text { Non- } \\
\text { believers } \\
(N=34)\end{array}$ & $\begin{array}{l}\text { Believers } \\
(N=33)\end{array}$ & $\begin{array}{c}\text { Non- } \\
\text { believers } \\
(N=20)\end{array}$ \\
\hline $\begin{array}{l}\text { Bible, } \\
\text { religious } \\
\text { education }\end{array}$ & $35(34 \%)$ & $2(6 \%)$ & $17(52 \%)$ & $2(10 \%)$ \\
\hline $\begin{array}{l}\text { NDE } \\
\text { accounts }\end{array}$ & $24(23 \%)$ & $1(3 \%)$ & $8(24 \%)$ & $1(5 \%)$ \\
\hline $\begin{array}{c}\text { fictional } \\
\text { books, } \\
\text { movies }\end{array}$ & $15(14 \%)$ & $5(15 \%)$ & $1(3 \%)$ & $1(5 \%)$ \\
\hline $\begin{array}{l}\text { nonfiction } \\
\text { books }\end{array}$ & $15(14 \%)$ & $6(18 \%)$ & $5(15 \%)$ & $1(5 \%)$ \\
\hline family & $22(21 \%)$ & $9(26 \%)$ & $6(18 \%)$ & $0(0 \%)$ \\
\hline $\begin{array}{l}\text { friends, } \\
\text { groups }\end{array}$ & $16(15 \%)$ & $5(15 \%)$ & $6(18 \%)$ & $1(5 \%)$ \\
\hline $\begin{array}{l}\text { another's } \\
\text { death }\end{array}$ & $5(5 \%)$ & $2(6 \%)$ & $2(6 \%)$ & $1(5 \%)$ \\
\hline $\begin{array}{l}\text { own ideas, } \\
\text { logic }\end{array}$ & $16(15 \%)$ & $8(24 \%)$ & $3(9 \%)$ & $10(50 \%)$ \\
\hline $\begin{array}{l}\text { don't know, } \\
\text { no answer }\end{array}$ & 20 (19\%) & $4(12 \%)$ & $3(9 \%)$ & $4(20 \%)$ \\
\hline
\end{tabular}

such a possibility. Questionnaires were completed by 174 students. This brings the total number of people participating in the project to 508, with 436 of these being students. Although the majority of the respondents were students, the results nonetheless are relevant to a general study of beliefs and their relationship to the NDE. Mary Reardon Castles and Ruth Beckmann Murray (1979) argued that random selection has little meaning in the field of death and dying. The important issue is to identify clearly the population being sampled. No population should be less interesting or important than another where questions of death and dying are concerned. For instance, since there is no typical social profile of the NDEr, all populations should be equally relevant to study. 
There were 57 males and 113 females who participated in Study 2, and 4 persons whose gender was not specified. The majority of these students were studying social science (148). The mean age was 20.

\section{Questionnaire}

The format and design of the survey instrument was identical to that described in Study 1 except for one detail. After question 1 concerning belief in postmortem existence, all respondents were asked to answer question 2 and 3 regardless of their beliefs. They were asked to imagine they actually do survive and to answer questions about what they might actually experience in that eventuality.

\section{Results}

For this sample the distribution of responses is shown in Table 4. Comparison of these data with those from the student sample in Study 1 indicates a highly significant difference $\left(\mathrm{X}^{2}=35.56 \mathrm{df}=2 ; \mathrm{p}<.001\right)$. There may be several explanations for this discrepancy. The two student samples may genuinely have differed; that is, rather different student populations may have been tapped in Study 1 and Study 2. For example, a unique feature of the sample in Study 1 was the large group of nursing students. On the other hand, there may have been a factor working against students' candidness in the earlier belief survey. In Study 1, respondents who acknowledged postmortem belief then had to give details about several aspects of that belief, whereas those who were unsure about their belief were not required to do so. In Study 2, on the other hand, all respondents were required to describe their expectations for facets of postmortem experience. There may have been a temptation for less motivated believers to claim to be unsure about

\section{Table 4}

Belief about surviving the first five minutes after death-Study 2

\begin{tabular}{lc}
\hline & Students $(n=174)$ \\
\hline will survive & $112(64 \%)$ \\
will not survive & $27(16 \%)$ \\
unsure & $35(20 \%)$ \\
\hline
\end{tabular}


their belief, thereby avoiding the time consuming task of answering question 2.

In Study 2, some 25-45\% of nonbelievers insisted that they did not know what to expect of various facets of a postmortem existence. This necessarily dilutes the incidence of specific expectations in comparison to that of believers' views in Study 1. While the lack of response among nonbelievers might be taken to signify an implacable determination not to countenance the notion of an afterlife, it might also reflect some nonbelievers' selective avoidance of, and lack of exposure to, social input about postmortem existence. In other words, there may well be good reason for their apparent ignorance of socially propagated expectations about the afterlife.

The expectations of postmortem experience within the complete sample for Study 2 are summarized in Table 2. Taking due account of many nonbelievers' lack of contribution to the above data, the table again documents the extent to which people's views of the first five minutes of postmortem experience accord with the NDE.

There are no major discrepancies between the overall patterns in these data and those of Study 1. Perhaps the emotional response of calmness is rather lower in people's expectations than in people's beliefs. Again, given the earlier consideration concerning the disparity between the two student samples, the interpretation of this difference is unclear.

The declared sources of expectations in Study 2 are summarized in Table 5. These data suggest that whereas all categories of respondents were able to use their religious education as a basis for generating their expectations, NDE accounts were a source of expectations solely for the believers. Perhaps because childhood religious education could not generally be avoided, believers and nonbelievers alike were able to draw on this information in conceptualizing a postmortem experience. Accounts of NDEs, however, can be avoided to some extent. We can decline to read the book about NDEs, we can turn off the TV documentary, and we can flip past the magazine article. Not only are nonbelievers able to avoid information on NDEs, they can selectively fail to memorize such information to the extent that they are exposed to it. Even if they sat through a segment of a television program on the NDE, the program's content would be recognized as incompatible with their beliefs and soon forgotten. In other words, because of nonbelievers' perception of the NDE as uninteresting, they genuinely may be unable to recall this material when faced with a question about the nature of a hypothetical afterlife. 
Table 5

Incidence of declared sources of expectation-Study 2

\begin{tabular}{lccr}
\hline & $\begin{array}{c}\text { Believers } \\
(N=112)\end{array}$ & $\begin{array}{c}\text { Nonbelievers } \\
(N=27)\end{array}$ & $\begin{array}{c}\text { Unsure } \\
(N=35)\end{array}$ \\
\hline Bible, religious education & $32(29 \%)$ & $5(19 \%)$ & $8(23 \%)$ \\
NDE accounts & $25(22 \%)$ & $0(0 \%)$ & $1(3 \%)$ \\
fictional books, movies & $26(23 \%)$ & $9(33 \%)$ & $20(57 \%)$ \\
nonfiction books & $15(13 \%)$ & $2(7 \%)$ & $1(3 \%)$ \\
family & $9(8 \%)$ & $2(7 \%)$ & $4(11 \%)$ \\
friends, groups & $8(7 \%)$ & $3(11 \%)$ & $5(14 \%)$ \\
another's death & $1(1 \%)$ & $0(0 \%)$ & $1(3 \%)$ \\
own ideas, logic & $13(12 \%)$ & $7(26 \%)$ & $4(11 \%)$ \\
don't know, no answer & $18(16 \%)$ & $7(26 \%)$ & $4(11 \%)$ \\
\hline
\end{tabular}

The inclination of nonbelievers to depict themselves as immune to social influences is again evident in this sample.

\section{Discussion}

In both studies there is a substantial minority of people who believe that they will experience elements of the NDE in the first five minutes after death. Generally these elements are cited more frequently than Biblical images. This is strong indication that accounts of NDEs have made a powerful impact on the community in general and the young student population in particular. This trend parallels those found by Allan Kellehear and Patrick Heaven (1989) and Barbara Walker and Robert Russell (1989) in their survey work. It cannot be concluded, of course, that actual NDEs are inspired by the publicity given to previous cases. After all, NDEs are known to have occurred prior to the wide and popular coverage of them. Our data nevertheless are by no means incompatible with the hypothesis that the NDE itself could be molded to some degree by socially propagated beliefs and expectations.

It is noteworthy also that the students who believed they will see a Biblical or heavenly setting did not report a belief they would see the immediate setting in which they die. These two beliefs form the basis of two quite separate sub-groups of the sample $\left(\mathrm{V}^{2}=3.84\right.$, $\mathrm{df}=1$; $\mathrm{p}<.05$; where $\mathrm{V}^{2}$ is $\mathrm{X}^{2}$ corrected for sample size [Rhoades and Overall, 1982]). This supports the methodological importance of differentiating 
between pareschatological beliefs and eschatological ones. Although studies that focus only on beliefs about heaven or hell are useful in exploring the imagery people may use, any such survey might also artificially exaggerate the differences between popular belief about postmortem existence and images of the NDE. Such observed differences might also merely reflect the fact that images of NDEs relate specifically to a short period after death.

The belief in meeting deceased pets was uncommon but nonetheless confined to the student sample. Possibly because the students were young a pet may have been the only deceased entity known to some of them. In this regard, it may be noted that pets are an (also infrequent) element of children's rather than adults' NDEs (Irwin, 1989).

Of some interest too is the finding that a small proportion (approximately $6 \%$ ) of the total sample of 508 respondents reported that they believe they would be frightened or anxious five minutes after death. For example, one student was unsure whether he would see God or Satan, heaven or hell, but described only one way he might feel: "emotionally distressed." Another student described her first five minutes in "a barren, futile land" where she might meet "another spirit or alien." She would be "unnerved" and "disillusioned." A businessman from the community sample described his belief about the first five minutes after death as finding himself "in a kaleidoscope of colour, moving in random swirls like a mist." He would be unable to recognize anyone and his experience would be "a confused picture, as in a dream." There would be a "confusion of sound, voices, nothing distinguishable-not musical." He would feel, understandably, "insecure, disorientated." Other students in this group described their feelings as "lost," "afraid," "frightened," "confused," "upset," and "scared." Two observations may be made about these responses, one methodological and the other theoretical.

Methodologically, these results show the importance of surveys of belief to be semistructured and to explore the emotional dimension of beliefs. George Gallup (1982), in his national U.S. survey, for example, failed to establish that negative emotions are part of some people's view of the afterlife. Although Gallup identified beliefs in hell, for example, and found some respondents who believed they might be bound for this place, a subsequent checklist did not canvass for beliefs about the nature of hell nor feelings about this (Gallup, 1982). The 13\% of the sample who rejected all offered statements concerning their beliefs about life after death may disguise the group who believe such a prospect could be negative and frightening to them. 
On a theoretical level, the reports of negative emotions from some of our respondents have implications for the psychology of dying. We cannot claim that the negative beliefs expressed by our respondents are the fundamental cause of negative NDEs. Indeed, it remains to be determined precisely how, if at all, the content of the NDE is socially influenced. Nevertheless, while beliefs might well influence NDE content they most certainly do influence experiencers' interpretations of their NDEs. In the latter respect, if people with negative emotional beliefs about survival actually do find themselves conscious "five minutes after death," their experiences might be viewed at the time or subsequently as disturbing irrespective of their content. If NDEs are commonly encountered by the dying, prior beliefs and expectations could be important as to whether the experiences are interpreted in comforting or disturbing ways. Perhaps this is part of the reason why so many religious and cultural prescriptions for dying conduct emphasize the importance of positive attitude and equanimity in the face of impending death.

The possible roles of social conditioning in the nature of and the experiencer's interpretation of the NDE warrant further investigation. There is a cogent case for such research to be undertaken in societies that have been little exposed to the publicity over NDEs characteristic of Western societies.

\section{References}

Ayer, A. J. (1988). Intimations of immortality: What I saw when I was dead. National Review, No. 40, 38-40.

Castles, M. R., and Murray, R. B. (1979). Dying in an institution Nurse-patient perspectives. New York, NY: Appleton-Century-Crofts.

Counts, D. A. (1983). Near-death and out-of-body experiences in a Melanesian society. Anabiosis: The Journal of NeanDeath Studies, 3, 115-135.

Daniel, A. (1983). Power, privilege and prestige: Occupations in Australia. Melbourne, Australia: Longman Cheshire.

Gallup, G., Jr. (1982). Adventures in immortality: A look beyond the threshold of death. New York, NY: McGraw-Hill.

Hick, J. H. (1976). Death and eternal life. San Francisco, CA: Harper and Row.

Irwin, H. J. (1987). Images of Heaven. Parapsychology Review, 18(1), 1-4.

Irwin, H. J. (1989). The near-death experience in childhood. Australian Parapsychological Review, 14, 7-11.

Kellehear, A., and Heaven, P. (1989). Community attitudes toward near-death experiences: An Australian study. Journal of Near-Death Studies, 7, 165-172.

Kellehear, A., Heaven, P., and Gao, J. (1990). Community attitudes toward near-death experiences: A Chinese study. Journal of Near-Death Studies, 8, 163-173.

Pasricha, S., and Stevenson, I. (1986). Near-death experiences in India: A preliminary report. Journal of Nervous and Mental Disease, 174, 165-170. 
Rhoades, H. M., and Overall, J. E. (1982). A sample size correction for Pearson chi-square in $2 \times 2$ contingency tables. Psychological Bulletin, 91, 418-423.

Ring, K. (1980). Life at death: $A$ scientific investigation of the near-death experience New York, NY: Coward, McCann and Geoghegan.

Schorer, C. E. (1985-86). Two native American near-death experiences. Omega, 16, 111113.

Walker, B. A., and Russell, R. D. (1989). Assessing psychologists' knowledge and attitudes toward near-death phenomena. Journal of Near-Death Studies, 8, 103-110. 